\title{
A preliminary study showing no association between methylation levels of C3 gene promoter and the risk of CAD
}

\author{
Gaojun Cai ${ }^{{ }^{* \dagger}}$, Zhiying Huang ${ }^{2+}$, Lei Yu ${ }^{1}$ and $\mathrm{Li} \mathrm{Li}^{1}$
}

\begin{abstract}
Objective: Coronary artery disease (CAD) is a multi-factor disease. Complement component 3 (C3) plays an important role in the development of CAD. The present study investigated the association between DNA methylation status of $C 3$ gene promoter and the risk of CAD.
\end{abstract}

Methods: One hundred CAD patients and 1 hundred age-and gender- matched controls were recruited in current study. Methylation levels in CpG island in C3 promoter were determined by the method of bisulfite amplicon sequencing.

Results: Methylation levels of four $\mathrm{CpG}$ sites in $\mathrm{C3}$ promoter were measured. There were no significant difference in methylation level of each CpG site between CAD patients and controls. Average methylation rate was also calculated. No significant difference in average methylation rate was observed between CAD and control groups. Stratified analyses based on EH, DM and smoking status were carried out, no significant association between C3 promoter methylation levels and the susceptibility of CAD was observed. Furthermore, seven haplotypes were established and no significant difference in haplotypes was observed between CAD and control groups. However, our study showed that C3 DNA methylation levels were positively associated with LDL-C levels.

Conclusion: The present study showed no association between methylation levels of C3 promoter and the risk of CAD. However, the methylation levels might be related to LDL-C levels.

Keywords: Complement component 3, Coronary artery disease, Methylation, Epigenetics

\section{Introduction}

Coronary artery disease (CAD) remains the leading cause of morbidity and mortality worldwide. With the rapid aging of the population, increased calorie consumption and decreased physical activity, the incidence of cardiovascular disease in some developing countries will increase steadily in future [1]. The interaction among environmental, genetic and epigenetic factors affects the occurrence and development of CAD, which has been accepted widely [2].

Epigenetic regulation, changing the expression of genes without changing the DNA sequence, plays an important role in the occurrence of various diseases.

\footnotetext{
* Correspondence: cgj982@126.com

${ }^{\dagger}$ Gaojun Cai and Zhiying Huang contributed equally to this work.

${ }^{1}$ Department of Cardiology, Wujin Hospital affiliated with Jiangsu University,

Changzhou, Jiangsu Province 213017, China

Full list of author information is available at the end of the article
}

In recent years, the research on the association between epigenetics and cardiovascular disease was investigated more and more deeperly [3]. Candidate genes and epigenome-wide association studies (EWAS) showed that DNA methylation, the most common and important epigenetic modification pattern, was related to cardiovascular disease [4-6].

Complement component 3 (C3), one of the important components of complement system, is the central molecule of complement activity pathway [7]. C3 is mainly synthesized and secreted by liver and adipose tissues, composing of $\alpha$ and $\beta$ chains. The $C 3$ gene is located in human chromosome 19p13.3-2. Several polymorphism sites in $\mathrm{C} 3$ have been associated with CAD. Previous studies have showed that the activity of C3 was associated with several CAD risk factors [7], such as essential hypertension, diabetic mellitus 
and obesity. In 2014, Jiang $\mathrm{H}$ et al. found that $\mathrm{C} 3$ level was associated with the occurrence and development of CAD [8]. Inhibiting the interaction between $\mathrm{C} 3$ and fibrinogen could reduce the cardiovascular events in diabetic patients [9]. The association of $C 3$ methylation and body mass index (BMI) has been previously reported in Spanish population [10]. However, up to now, no study has designed to explore the relationship between $C 3$ promoter methylation and the CAD risk. Herein, we performed this case-control study to investigate whether $C 3$ methylation was associated with the risk of CAD and lipid profiles in a Chinese Han population.

\section{Materials and methods}

\section{Study population}

One hundred CAD patients (66 males and 34 females, mean age $64.1 \pm 10.9$ years) and 1 hundred age-and gender- matched controls (54 males and 46 females, mean age $63.1 \pm 8.2$ years) were recruited from the Department of Cardiology in Wujin Hospital affiliated to Jiangsu University between September 2013 to June 2017. The method of propensity score matching was used to select the subject. All subjects underwent coronary angiography (CAG) examination. The diagnosis of CAD was described in our previous studies [11]. CAD severity was substituted by the number of stenotic coronary artery. CAD patients were divided into three groups according to the number of stenotic coronary artery (one, two and three). The controls were who had angina-like chest pain and also underwent CAG examination in the same period. According to the results of CAG, controls had a luminal stenosis of $<50 \%$ in the major coronary arteries. As a result of the destruction of some serum samples, among the 200 participants, only 44 subjects were selected to detect for serum C3 levels, including $31 \mathrm{CAD}$ patients and 13 controls. People with asthma, malignancy, serious kidney or hepatic disease were excluded. Patients taking lipidlowering drugs in 3 months prior to the study, which might affect the lipid metabolism, were also excluded from the study.

The study protocol was approved by the Ethics Committee of our hospital and informed consent was obtained from all enrolled patients.

\section{Biochemical analysis}

After overnight fasting, venous blood was drawn to detect biochemical data. The methods of detection of lipid levels, including TC, triglyceride (TG), high density lipoprotein cholesterol (HDL-C) and LDL-C, apolipoprotein A1 (Apo A1) and Apo B, were
Table 1 Baseline characteristics of involved CAD patients and controls

\begin{tabular}{llll}
\hline Characteristics & CAD $(n=100)$ & Control $(n=100)$ & $P$ \\
\hline Age, years & $64.1 \pm 10.9$ & $63.1 \pm 8.2$ & 0.452 \\
Male, $n(\%)$ & $66(66)$ & $54(54)$ & 0.112 \\
EH, $n(\%)$ & $66(66)$ & $61(61)$ & 0.557 \\
DM, $n(\%)$ & $26(26)$ & $16(16)$ & 0.118 \\
Smoking, $n(\%)$ & $44(44)$ & $32(32)$ & 0.109 \\
TC, mmol// & $4.70 \pm 1.16$ & $4.44 \pm 0.81$ & 0.064 \\
TG, mmol// & $1.57(1.06-2.40)$ & $1.37(0.96-2.11)$ & 0.118 \\
HDL-C, mmol/l & $1.06 \pm 0.23$ & $1.20 \pm 0.33$ & $<0.001$ \\
LDL-C, mmol/l & $3.04 \pm 0.98$ & $2.71 \pm 0.75$ & 0.009 \\
AppAl, g/l & $1.17 \pm 0.20$ & $1.31 \pm 0.25$ & $<0.001$ \\
ApoB, g/l & $1.00 \pm 0.32$ & $0.94 \pm 0.22$ & 0.081 \\
\hline CAD coronary artery disease, $E H$ essential hypertension, DM diabetes mellitus, \\
TC total cholesterol, TG triglyceride, HDL-C high-density lipoprotein cholesterol, \\
LDL-C low-density lipoprotein cholesterol
\end{tabular}

described in our previous studies [11]. Serum C3 levels were detected by radio-immunoassay method.

\section{DNA extraction and bisulfite amplicon sequencing}

Genomic DNA was extracted from whole blood. The methods were performed as previously described [12]. The quality and concentration of genomic DNA were assessed by gel electrophoresis and Nanodrop 2000 spectrophotometer (NanoDrop technologies, Wlimington, DE, USA). The concentration of DNA was more than $20 \mathrm{ng} / \mu \mathrm{L}$ and the $260 / 280$ absorbance ratio was between $1.8 \sim 2.0$.

CpG islands in the promoter of $C 3$ gene were selected according to the following criteria: 1) 200 bp minimum length; 2) > 50\%CG contents; 3 ) $>0.60$ observed/expected the ratio of $\mathrm{CpG}$ dinucleotides. Only one region with four CpG sites met the inclusion criteria and was involved in the study. The detailed information of the four $\mathrm{CpG}$ sites lists in Additional file 1: Table S1. CpG sites were named as their relative distance to transcriptional start site (TSS).

Table 2 Methylation levels of four CpG sites in C3 promoter between $C A D$ and controls

\begin{tabular}{lllll}
\hline CpG site & CAD (\%) & Control (\%) & $P$ & $P^{\text {a }}$ \\
\hline 1 & $56.1 \pm 6.7$ & $54.5 \pm 8.3$ & 0.124 & 0.123 \\
2 & $57.3 \pm 6.8$ & $55.9 \pm 8.0$ & 0.195 & 0.174 \\
3 & $61.1 \pm 6.6$ & $59.8 \pm 7.5$ & 0.180 & 0.175 \\
4 & $59.6 \pm 6.8$ & $58.6 \pm 7.8$ & 0.192 & 0.169 \\
Average & $58.5 \pm 6.6$ & $57.1 \pm 7.8$ & 0.165 & 0.153 \\
\hline
\end{tabular}

C3 component 3, CAD coronary artery disease, $P^{\mathrm{a}}$ adjustment for $\mathrm{EH}, \mathrm{DM}$, and smoking status 


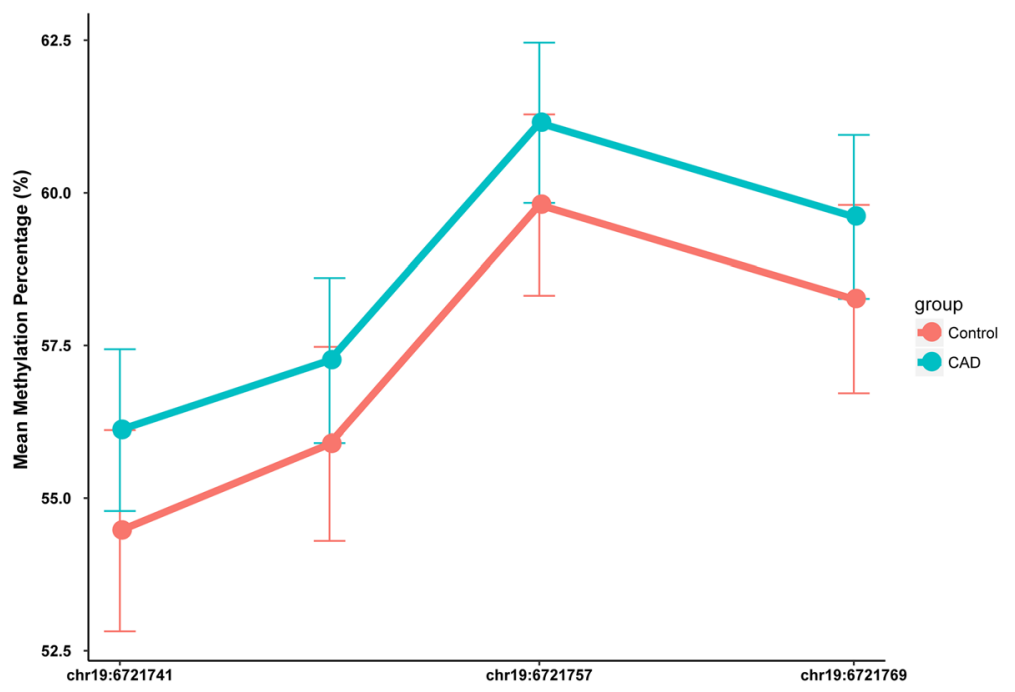

Fig. 1 The methylation status of four $\mathrm{CpG}$ sites of $\mathrm{C} 3$ promoter. The $x$-axis represents the genomic positions of the $\mathrm{CpG}$ sites; The $y$-axis represents the mean methylation percentage; The red line represents the control group; The blue line represents the CAD group

The method of bisulfite amplicon sequencing was carried out to measure DNA methylation levels. Bisulfite conversion was performed using the EZ DNA Methylation-Glod Kit (ZYMO, CA, USA) according to manufacturer's standard protocol, which was reported by Zhou SY et al. [13]. The bisulfite conversion rate of each sample was $\geq 99 \%$ in our study and no significant difference was found between $\mathrm{CAD}$ and controls groups. The primers used for polymerase chain reaction (PCR) were designed by Primer 3 software (http://primer3.ut.ee/) and the information of primers was shown in Additional file 2: Table S2. After PCR amplification (HotStar Taq polymerase, TaKaRa, Dalian, China) and library construction, products were sequenced on Illumina Hiseq 2500 Benchtop Sequencer (CA, USA). All samples achieved a mean

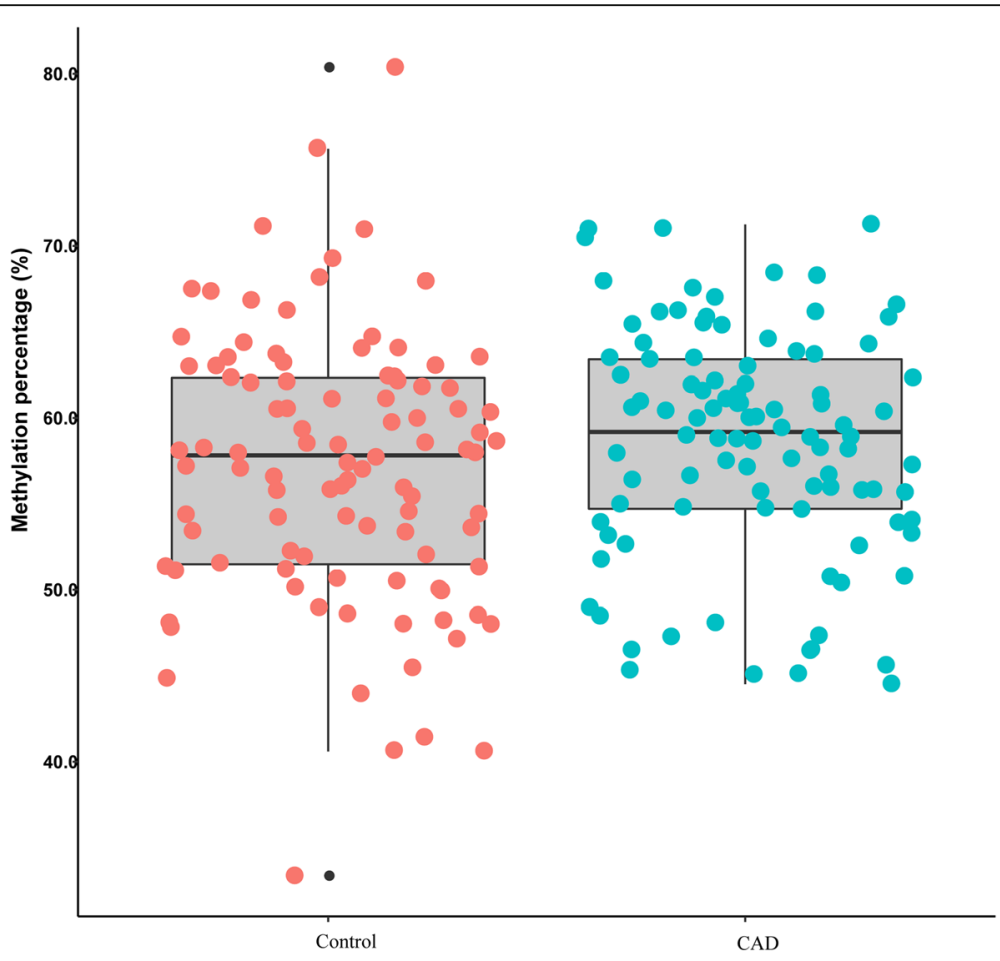

Fig. 2 The mean methylation status of C3 promoter 
Table 3 Haplotype of CpG sites between CAD patients and controls (\%)

\begin{tabular}{lllll}
\hline Haplotype & Depth & CAD (\%) & Control (\%) & $P$ \\
\hline CCCC & 79,034 & $49.2 \pm 5.9$ & $47.8 \pm 7.2$ & 0.135 \\
TाTा & 60,288 & $34.2 \pm 6.6$ & $35.4 \pm 7.6$ & 0.179 \\
TCCC & 5947 & $3.6 \pm 1.2$ & $3.8 \pm 2.3$ & 0.671 \\
TTCT & 4449 & $2.5 \pm 0.8$ & $2.6 \pm 0.8$ & 0.358 \\
CTCC & 4221 & $2.7 \pm 0.9$ & $2.6 \pm 0.9$ & 0.283 \\
CCCT & 3688 & $2.3 \pm 1.0$ & $2.2 \pm 0.7$ & 0.890 \\
CCTC & 3666 & $2.3 \pm 0.7$ & $2.3 \pm 0.7$ & 0.772 \\
\hline
\end{tabular}

$C A D$ coronary artery disease

coverage of $>1000 \mathrm{X}$. Q30 of each sample was more than $98.22 \%$.The calculating methods of methylation level of each CpG site and average methylation level of $\mathrm{CpG}$ region were reported by previous study [14].

\section{Statistical analysis}

Normality of quantitative variables was assessed by Kolmogorov-Smirnov test. If the data was normal distribution, it was presented as mean \pm standard deviation (SD) and compared using an independent samples $t$ test; otherwise, it was presented as median (interquartile range) and compared using MannWhitney $U$ test. Multivariable logistic regression was used to determine associations between CpG sites in $C 3$ and CAD, which was adjusted for smoking, EH and DM. Subgroup analyses based on status of smoking, EH and DM were carried out. And the results were adjusted by Bonferroni correction (for average methylation, corrected $P<0.017$; for each CpG site, corrected $P<0.004)$. Categorical variables were expressed as frequencies and percentages and compared using a Chi-square test. Person correlation analysis was used to evaluate the correlation between methylation level and lipid profiles. The haplotypes of CpG sites in C3 gene were counted directly, according to the results of detection at the $\mathrm{CpG}$ site on the sequencing fragment. All data were analyzed using SPSS 17.0 software package (SPSS Inc., Chicago, Illinois). A two-sided $p$-value $<0.05$ was considered statistically significant.

\section{Results}

\section{Baseline characteristics}

Table 1 shows the baseline characteristics of involved CAD patients and controls. Compared to controls, LDL-C levels in CAD patients were significantly higher $(2.71 \pm 0.75$ vs $3.04 \pm 0.98 \mathrm{mmol} / \mathrm{l}, \quad P=0.009)$; whereas, HDL-C and ApoAI levels in patients were significantly lower than those in controls.

\section{CpG methylation levels of C3promoter in CAD and controls}

Firstly, methylation levels of four $\mathrm{CpG}$ sites located at the C3 promoter locus were assessed (Table 2, Fig. 1). There were no significant difference in methylation level of each CpG site between CAD patients and controls. Average methylation rate was also calculated. No significant difference in average methylation rate was observed between $\mathrm{CAD}$ and control groups (Fig. 2). CAD severity was substituted by the number of stenotic coronary artery. CAD patients were divided into three groups according to the number of stenotic coronary artery (one, two and three). There was no difference between CpG sites methylation and CAD severity (data not shown). Stratified analyses based on EH, DM and smoking status were carried out, no significant association between C3 promoter methylation levels and the susceptibility of CAD was observed (data showing in Additional file 3: Table S3-S5).

\section{Haplotype of CpG sites between CAD patients and controls}

Total seven haplotypes were detected (Table 3 ). The haplotypes were not significantly different between CAD and control groups.

\section{Methylation levels of C3 promoter and serum lipid profiles}

As shown in Fig. 3a-e, methylation levels of four $\mathrm{CpG}$ sites was positively associated with LDL-C levels (site 1: $r=0.152, P=0.031$; site $2: r=0.191, P=0.007$; site 3: $r=0.176, P=0.013 ;$ site $4: \quad r=0.166 ; P=0.019)$. Additionally, the average methylation rate was also positively associated with LDL-C levels $(r=0.174, P=0.014)$. After correcting for age, the correlation remained significant. According to the median of methylation levels, patients were divided into low methylation and high methylation groups. We observed the LDL-C levels in high methylation group were significantly higher than those in low methylation group for site 1, 2 and average (Fig. 4a-c). There was no correlation between methylation levels of $\mathrm{CpG}$ sites in $\mathrm{C} 3$ gene and TC, TG and HDL-C levels (Additional file 4: Table S6).

\section{Discussion}

To our knowledge, it was the first study to explore the relationship between methylation levels in C3 promoter and CAD risk and lipid profiles.

DNA methylation is the most common and important epigenetic modification. General speaking, when the gene promoter $\mathrm{CpG}$ island is in hypermethylated status, its expression is inhibited; otherwise, the 

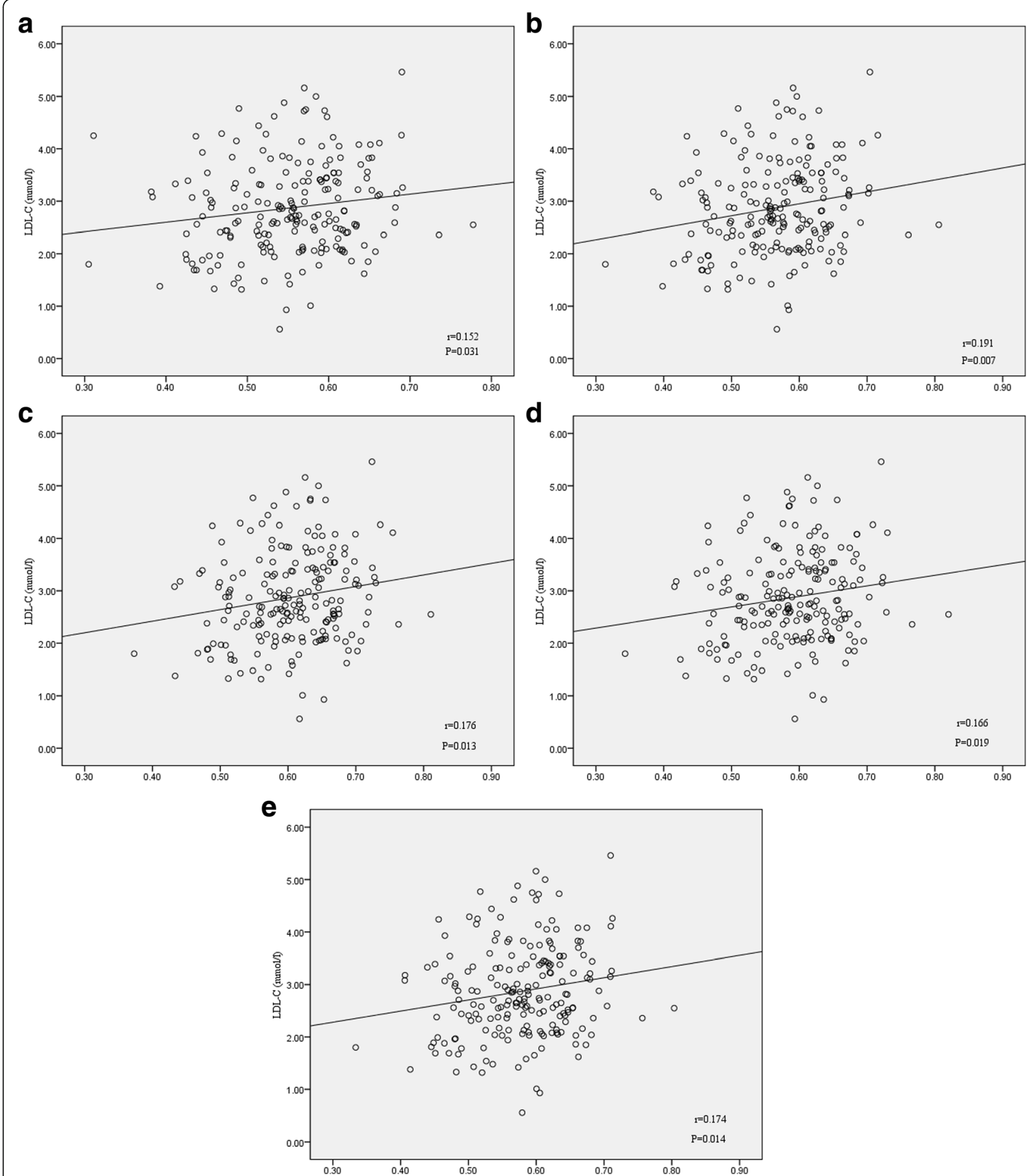

Fig. 3 Pearson's correlation between C3 DNA methylation levels and LDL-C levels. a CpG site 1; b CpG site 2; c CpG site 3; d CpG site 4; e Average $\mathrm{CpG}$ sites

expression of the gene is up-regulated. However, there is also discrepancy in the association in some genes, such as ABCA1 [4, 15], PON1 [16, 17], etc. Unlike the changes in DNA itself, many epigenetic changes are reversible, which provides an optimistic outlook for the treatment of the diseases [18]. Environmental factors can affect the methylation of DNA promoter such as smoking [19], life stress [20], dietary [21], etc. For example, Park SL et al. found that internal smoking dose was associated with 

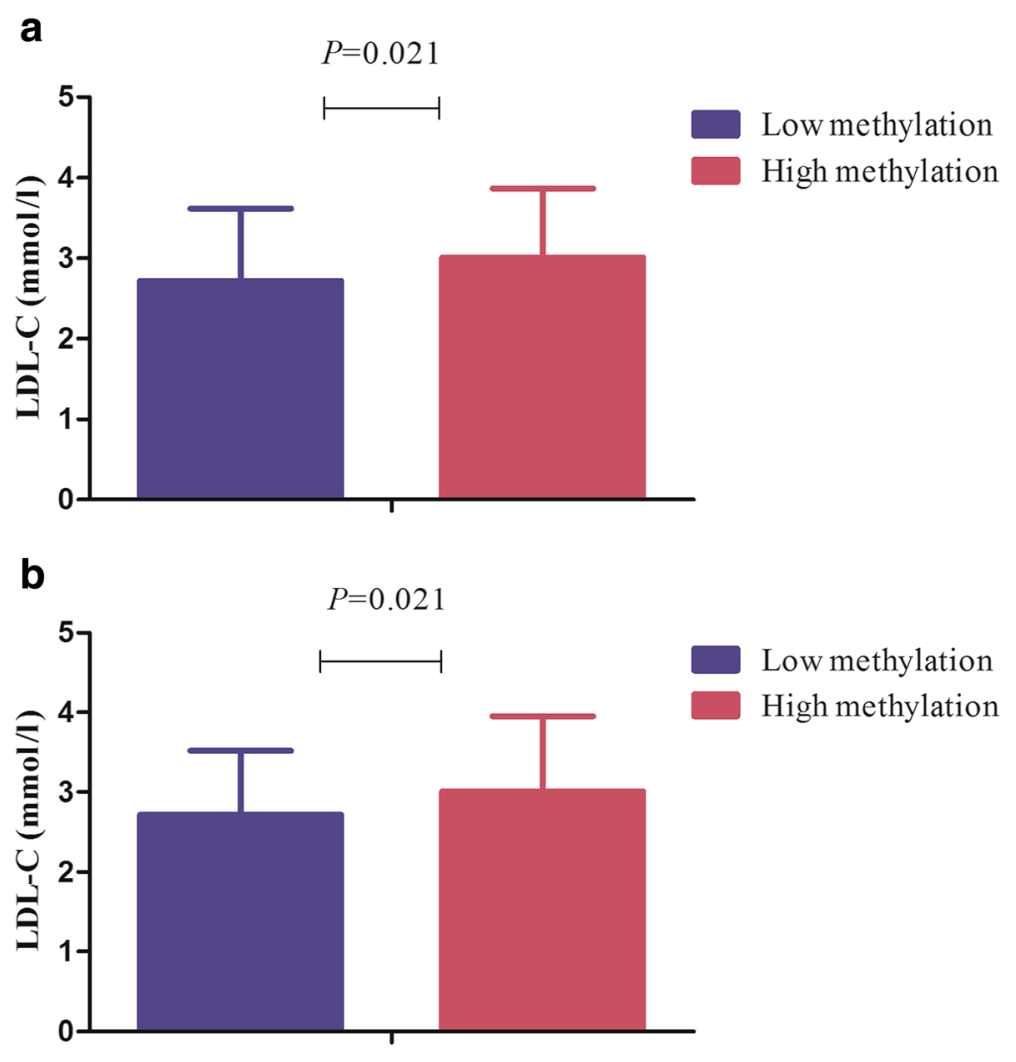

Low methylation

High methylation

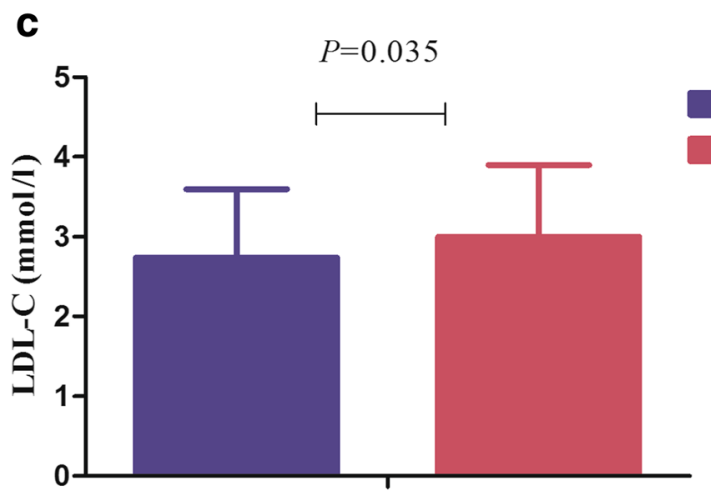

Low methylation

High methylation

Fig. 4 Association of methylation level of C3 promoter with LDL-C levels. a CpG site 1; b CpG site 2; c average CpG sites

increased DNA methylation in circulating leukocytes at specific sites in Native Hawaiian smokers [19]. In a cross-sectional study conducted in 5186 Australian adult participants, the authors suggested that dietary intake of one-carbon metabolism nutrients was associated with blood DNA methylation [21].

In recent year, studies focusing on the relationship between epigenetics and CAD revealed that aberrant methylation of gene promoter might be implied in the etiology of CAD [6, 22]. As an important component of complement system, C3 may be involved in the occurrence and development of CAD by direct and indirect mechanisms. In 2018, Castellano-Castillo $\mathrm{D}$ et al. conducted a study to verify whether C3 DNA methylation level in adipose tissues associated to body mass index (BMI) or obesity-associated metabolic diseases [10]. In their study, C3 DNA methylation and $\mathrm{C} 3$ mRNA were detected in 60 participants who were divided into three groups by BMI value and mean methylation level for seven CpG sites in C3 promoter was calculated. The results showed that $C 3$ methylation levels were positively associated with BMI and leptin. However, no significant association between C3 DNA methylation and mRNA expression were observed.

In the present study, methylation levels of four CpG sites, located upstream of $C 3$ promoter, were measured. We failed to find an association between methylation of $\mathrm{CpG}$ 
sites in $C 3$ promoter and the risk of CAD. Subgroup analysis stratified by EH, DM and smoking status got the consistent results. Furthermore, seven haplotypes were established and no significant difference in haplotypes was observed between CAD and control groups. Interestingly, our study showed that C3 DNA methylation levels were positively associated with LDL-C levels, although the Person correlation coefficient ( $r$ value) was relatively low. Unlike cancer samples, it is difficult to obtain coronary artery tissue. So, samples in most studies about DNA methylation and CAD were selected from blood cells [23]. The methylation status in different tissues from the same subjects was discrepancy [24]. The methylation level in blood cells might differ from that in vascular tissues. So, we should interpret the results cautiously.

There were several limitations in this study. First, the present study was a hospital-based case-control study. The diagnosis of control was based on the result of CAG and the criteria was luminal stenosis of main coronary artery less than $50 \%$, which might lead to selection bias. Second, we did not detect the C3 levels because of the loss of serum samples. So, we did not determine whether the DNA methylation affected C3 expression. Third, only one CpG region was selected to determine the methylation of $\mathrm{CpG}$ sites. In addition, the sample size was relatively small in our study. Therefore, large sample and multi-center studies are needed to be performed to confirm our results. Finally, this was a retrospective study and the baseline data were consulted from the electronic medical record. Because of part of CAG images being not obtained, we could not analyze the relationship between CAD severity/degree of stenosis treated as the continuous variable and DNA methylation. Some environmental factors' data, such as drinking dose, mental stress and economic condition, could not be obtained. Environmental factor might affect the DNA methylation, which has been well established. We could not analyze the influence of these factors on C3 DNA methylation. Well designed and prospective study need to be investigated.

\section{Conclusions}

In summary, the present study suggested that $C 3$ promoter methylation might not be associated with CAD risk. However, the methylation levels might be related to LDL-C levels.

\section{Additional files}

Additional file 1: Table S1. Methylated CpG sites measured in this study. (DOCX $12.8 \mathrm{~kb}$ )

Additional file 2: Table S2. Primer sequences for C3 gene (start and end site were named as its relative distance to TSS). (DOCX $12.8 \mathrm{~kb}$ )

Additional file 3: Table S3. Subgroup analysis of methylation levels of CPG sites in C3 promoter between CAD and controls by smoking status. Table S4. Subgroup analysis of methylation levels of CpG sites in C3 promoter between CAD and controls by EH status. Table S5. Subgroup analysis of methylation levels of CpG sites in C3 promoter between CAD and controls by DM status. (ZIP $34.7 \mathrm{~kb}$ )

Additional file 4: Table S6. Relationship between methylation levels of CpG sites in C3 gene and TC, TG and HDL-C levels. (DOCX $13.1 \mathrm{~kb}$ )

\section{Abbreviations}

C3: Component 3; CAD: Coronary artery disease; CAG: Coronary angiography; DM: Diabetes mellitus; EH: Essential hypertension; HDL-C: High-density lipoprotein cholesterol; LDL-C: Low-density lipoprotein cholesterol; TC: Total cholesterol; TG: Triglyceride

\section{Acknowledgements}

We thank all our colleagues at the Department of Cardiology, Wujin Hospital, affiliated with Jiangsu University. We also thank Genesky Biotechnologies Inc. (Shanghai) for their technical support in the sequencing.

\section{Funding}

This study was supported by the Jiangsu Youth Medical Talents Project (QNRC2016310), Changzhou Science and Technology Development (CJ20160004)

\section{Availability of data and materials}

The datasets used and/or analyzed during the current study are available from the corresponding author on reasonable request.

\section{Authors' contributions}

All authors have read the manuscript and agreed with the contents. GJC and ZYH conceived and designed the experiments; GJC, LY and LL performed the experiments; GJC and LY analyzed the data; GJC contributed reagents/ materials/analysis tools; GJC and ZYH wrote the paper. All authors read and approved the final manuscript.

Ethics approval and consent to participate

This study was performed in accordance with the Declaration of Helsinki and approved by the Ethics Committee of Jiangsu University. All participants

signed an informed consent.

Consent for publication

Not applicable

Competing interests

The authors declare that they have no competing interests.

\section{Publisher's Note}

Springer Nature remains neutral with regard to jurisdictional claims in published maps and institutional affiliations.

\section{Author details}

${ }^{1}$ Department of Cardiology, Wujin Hospital affiliated with Jiangsu University, Changzhou, Jiangsu Province 213017, China. ${ }^{2}$ Department of Pediatrics, No. 2 Hospital of Changzhou, Changzhou 213001, Jiangsu, China.

Received: 11 September 2018 Accepted: 17 December 2018

Published online: 05 January 2019

\section{References}

1. Shen CX, Ge JB. Epidemic of cardiovascular disease in China. Current perspective and prospects for the future. Circulation. 2018;138:342-4.

2. Lei HP, Yu XY, Wu H, Kang YH, Zhong WP, Cai LY, Zhang MZ, Chen JY, Mai $L P$, Ding QS, Yang M, Zhong SL. Effects of PON1 Gene Promoter DNA Methylation and Genetic Variations on the Clinical Outcomes of Dual Antiplatelet Therapy for Patients Undergoing Percutaneous Coronary Intervention. Clin Pharmacokinet. 2018;57(7):817-29. https://doi.org/10.1007/ s40262-017-0595-4 PMID:28875477.

3. Duan L, Liu C, Hu J, Liu Y, Wang J, Chen G, Li Z, Chen H. Epigenetic mechanisms in coronary artery disease: The current state and prospects. Trends Cardiovasc Med. 2018;28(5):311-9. https://doi.org/10.1016/j.tcm.2017. 12.012 PMID: 29366539. 
4. Ghaznavi H, Mahmoodi K, Soltanpour MS. A preliminary study of the association between the ABCA1 gene promoter DNA methylation and coronary artery disease risk. Mol Biol Res Commun. 2018;7(2):59-65. https://doi.org/10.22099/mbrc.2018.28910.1312 PMID:30046619.

5. Nakatochi M, Ichihara S, Yamamoto K, Naruse K, Yokota S, Asano H, Matsubara T, Yokota M. Epigenome-wide association of myocardial infarction with DNA methylation sites at loci related to cardiovascular disease. Clin Epigenetics. 2017;9:54. https://doi.org/10.1186/s13148017-0353-3 PMID:28515798

6. Li J, Zhu X, Yu K, Jiang H, Zhang Y, Deng S, Cheng L, Liu X, Zhong J, Zhang X, He M, Chen W, Yuan J, Gao M, Bai Y, Han X, Liu B, Luo X, Mei W, He X, Sun S, Zhang L, Zeng H, Sun H, Liu C, Guo Y, Zhang B, Zhang $Z$, Huang J, Pan A, Yuan $Y$, Angileri $F$, Ming B, Zheng $F$, Zeng Q, Mao X, Peng Y, Mao Y, He P, Wang QK, Qi L, Hu FB, Liang L, Wu T. Genome-Wide Analysis of DNA Methylation and Acute Coronary Syndrome. Circ Res. 2017;120(11):1754-67. https://doi.org/10.1161/ CIRCRESAHA.116.310324 PMID:28348007.

7. Ursini F, Abenavoli L. The emerging role of complement C3 as a biomarker of insulin resistance and cardiometabolic diseases: preclinical and clinical evidence. Rev Recent Clin Trials. 2018;13(1):61-8. https://doi.org/10.2174/ 1574887112666171128134552 PMID: 29189176.

8. Jiang H, Guo M, Dong L, Cao C, Wang D, Liang X, Guo F, Xing Z, Bu P, Liu J. Levels of acylation stimulating protein and the complement component 3 precursor are associated with the occurrence and development of coronary heart disease. Exp Ther Med. 2014;8(6):1861-6. https://doi.org/10.3892/etm. 2014.2018 PMID:25371745.

9. King R, Tiede C, Simmons K, Fishwick C, Tomlinson D, Ajjan R. Inhibition of complement C3 and fibrinogen interaction: a potential novel therapeutic target to reduce cardiovascular disease in diabetes. Lancet. 2015;385(Suppl 1):S57. https://doi.org/10.1016/S0140-6736(15)60372-5 PMID: 26312879.

10. Castellano-Castillo D, Moreno-Indias I, Fernandez-Garcia JC, ClementePostigo M, Castro-Cabezas M, Tinahones FJ, Queipo-Qrtuño Ml, Cardona F. Complement factor C3 methylation and mRNA expression is associated to BMI and insulin resistance in obesity. Genes (Basel). 2018;9(8):E410. https:// doi.org/10.3390/genes9080410 PMID:30104553.

11. Cai G, Zhang B, Shi G, Weng W, Yang L, Xue S. Endothelial lipase genetic polymorphisms and lipid-lowering response in patients with coronary artery disease on rosuvastatin. Lipids Health Dis. 2016;15(1):148. https://doi.org/10. 1186/s12944-016-0295-3 PMID: 27600285.

12. Cai G, Zhang B, Ma C, Shi G, Weng W, Xue S. Associations of rs3744841 and rs3744843 polymorphisms in endothelial lipase gene with risk of coronary artery disease and lipid levels in a Chinese population. PLoS One. 2016;11(9): e0162727. https://doi.org/10.1371/journal.pone.0162727 PMID: 27612170.

13. Zhou S, Cai B, Zhang Z, Zhang Y, Wang L, Liu K, Zhang H, Sun L, Cai H, Lu G, Liu X, Xu G. CDKN2B methylation and aortic arch calcification in patients with ischemic stroke. J Atheroscler Thromb. 2017;24(6):609-20. https://doi. org/10.5551/jat.36897 PMID: 27773886.

14. Pu W, Wang C, Chen S, Zhao D, Zhou Y, Ma Y, Wang Y, Li C, Huang Z, Jin L, Guo S, Wang J, Wang M. Targeted bisulfite sequencing identified a panel of DNA methylation-based biomarkers for esophageal squamous cell carcinoma (ESCC). Clin Epigenetics. 2017;9:129. https://doi.org/10.1186/ s13148-017-0430-7 PMID: 29270239.

15. Talens RP, Jukema JW, Trompet S, Kremer D, Westendorp RG, Lumey LH, Sattar N, Putter H, Slagboom PE, Heijmans BT, PROSPER Group. Hypermethylation at loci sensitive to the prenatal environment is associated with increased incidence of myocardial infarction. Int J Epidemiol. 2012; 41(1):106-15. https://doi.org/10.1093/ije/dyr153 PMID:22101166.

16. Gómez-Uriz AM, Goyenechea E, Campión J, de Arce A, Martinez MT, Puchau B, Milagro Fl, Abete I, Martínez JA, Lopez de Munain A. Epigenetic patterns of two gene promoters (TNF- $a$ and PON) in stroke considering obesitycondition and dietary intake. J Physiol Biochem. 2014;70(2):603-14. https://doi.org/10.1007/s13105-014-0316-5 PMID:24500802.

17. Fiorito G, Guarrera S, Valle C, Ricceri F, Russo A, Grioni S, Mattiello A, Di Gaetano C, Rosa F, Modica F, lacoviello L, Frasca G, Tumino R, Krogh V, Panico S, Vineis P, Sacerdote C, Matullo G. B-vitamins intake, DNA-methylation of one carbon metabolism and homocysteine pathway genes and myocardial infarction risk: the EPICOR study. Nutr Metab Cardiovasc Dis. 2014;24(5):483-8. https://doi.org/10.1016/j. numecd.2013.10.026 PMID:24418380.
18. Xu S, Pelisek J, Jin ZG. Atherosclerosis is an epigenetic disease. Trends Endocrinol Metab. 2018. https://doi.org/10.1016/j.tem.2018.04.007 PMID: 29753613.

19. Park SL, Patel YM, Loo LWM, Mullen DJ, Offringa IA, Maunakea A, Stram DO, Siegmund K, Murphy SE, Tiirikainen M, Le Marchand L. Association of internal smoking dose with blood DNA methylation in three racial/ethnic populations. Clin Epigenetics. 2018;10(1):110. https://doi.org/10.1186/s13148018-0543-7 PMID:30139389.

20. Santos HP Jr, Nephew BC, Bhattacharya A, Tan X, Smith L, Alyamani RAS, Martin EM, Perreira K, Fry RC, Murgatroyd C. Discrimination exposure and DNA methylation of stress-related genes in Latina mothers. Psychoneuroendocrinology. 2018;98:131-8. https://doi.org/10.1016/j. psyneuen.2018.08.014 PMID:30144780.

21. Chamberlain JA, Dugué PA, Bassett JK, Hodge AM, Brinkman MT, Joo JE, Jung $\mathrm{CH}$, Makalic E, Schmidt D F, Hopper JL, Buchanan DD, English DR, Southey MC, Giles GG, Milne RL. Dietary intake of one-carbon metabolism nutrients and DNA methylation in peripheral blood. Am J Clin Nutr. 2018 https://doi.org/10.1093/ajcn/nqy119 PMID:30101351.

22. Li D, Yan J, Yuan Y, Wang C, Wu J, Chen Q, Song J, Wang J. Genome-wide DNA methylome alterations in acute coronary syndrome. Int J Mol Med. 2018;41(1):220-32. https://doi.org/10.3892/ijmm.2017.3220 PMID:29115576.

23. Fernández-Sanlés A, Sayols-Baixeras S, Subirana I, Degano IR, Elosua R. Association between DNA methylation and coronary heart disease or other atherosclerotic events: a systematic review. Atherosclerosis. 2017;263:325-33. https://doi.org/10.1016/j.atherosclerosis.2017.05.022 PMID: 28577936.

24. Thomas M, Knoblich N, Wallisch A, Glowacz K, Becker-Sadzio J, Gundel F, Brückmann C, Nieratschker V. Increased BDNF methylation in saliva, but not blood, of patients with borderline personality disorder. Clin Epigenetics. 2018;10(1):109. https://doi.org/10.1186/s13148-018-0544-6 PMID: 30134995.
Ready to submit your research? Choose BMC and benefit from:
- fast, convenient online submission
- thorough peer review by experienced researchers in your field
- rapid publication on acceptance
- support for research data, including large and complex data types
- gold Open Access which fosters wider collaboration and increased citations
- maximum visibility for your research: over $100 \mathrm{M}$ website views per year
At BMC, research is always in progress.
Learn more biomedcentral.com/submissions 